\title{
Surgical Roles in the Management of Metachronus Para-aortic Lymph Node Recurrence and Synchronous Para-aortic Lymph Node Metastasis in Colorectal Cancer Patients
}

\author{
Osama Abd-Elaziz ${ }^{1}$ Ramadan M. Ali ${ }^{1}$ Mohamed Farouk Amin ${ }^{1}$ Ahmed M. Fahmy ${ }^{2}$ \\ Shereen Elshorbagy ${ }^{3}$ Doaa Mandour ${ }^{4}$ Rehab Hemeda ${ }^{4}$ Ola A. Harb ${ }^{5}$ Amr Samir ${ }^{6}$ \\ Elsayed I. El-Hendawy ${ }^{1}$
}

${ }^{1}$ Department of General Surgery, Faculty of Medicine, Zagazig University, Zagazig, Egypt

2 Department of Anesthesia and Intensive Care, Faculty of Medicine, Zagazig University, Zagazig, Egypt

${ }^{3}$ Department of Medical Oncology, Faculty of Medicine, Zagazig University, Zagazig, Egypt

${ }^{4}$ Department of Clinical Oncology and Nuclear Medicine, Faculty of

Medicine, Zagazig University, Zagazig, Egypt

${ }^{5}$ Department of Pathology, Faculty of Medicine, Zagazig University,

Zagazig, Egypt

${ }^{6}$ Department of Internal Medicine, Faculty of Medicine, Zagazig

University, Zagazig, Egypt

| Coloproctol 2022;42(2):131-139.

\section{Abstract \\ Keywords \\ - colorectal cancer \\ - metachronous para- aortic lymph node recurrence \\ - synchronous para- aortic lymph node metastasis \\ - surgery}

\begin{abstract}
Address for correspondence Ola A. Harb, MD, PhD, Department of
Address for correspondence Ola A. Harb, MD, PhD, Department of 44519 (e-mail: olaharb2015@gmail.com).
\end{abstract}

Background The relative rarity of synchronous para-aortic lymph node (PALN) metastasis (SPM) and metachronous PALN recurrence (MPR) in colorectal carcinoma (CRC) patients leads to a limited number of studies on patient management, and no treatment guidelines have been established to date.

Objective To assess the prognostic, predictive roles, and long-term outcomes of different management strategies for isolated MPR and SPM in CRC patients to establish the best one.

Materials and Methods We included 35 CRC patients with isolated MPR and 25 patients with isolated SPM who underwent curative R0 resection. We performed PALN dissection (PALND) in 15 cases in MPR group and in 10 cases in the SPM group; all remaining patients in both groups underwent chemoradiotherapy (CRT) without further surgical intervention. During the study period of about 5 years, we compared the patients who underwent PALND and those who underwent CRT.

Results The overall survival and recurrence-free survival rates were significantly longer in patients who underwent PALND ( $p=0.049$ and 0.036 respectively). received

July 24, 2021

accepted after revision

October 25, 2021

published online

January 31, 2022
DOI https://doi.org/

$10.1055 / \mathrm{s}-0042-1742310$ ISSN 2237-9363. (c) 2022. Sociedade Brasileira de Coloproctologia. All rights reserved.

This is an open access article published by Thieme under the terms of the Creative Commons Attribution-NonDerivative-NonCommercial-License, permitting copying and reproduction so long as the original work is given appropriate credit. Contents may not be used for commercial purposes, or adapted, remixed, transformed or built upon. (https://creativecommons.org/ licenses/by-nc-nd/4.0/)

Thieme Revinter Publicações Ltda., Rua do Matoso 170, Rio de Janeiro, RJ, CEP 20270-135, Brazil 
Conclusions We showed that PALND in cases of CRC patients with SPM and MPR previously submitted to R0 resection was associated with favorable outcomes and better patient survival.

\section{Introduction}

Approximately 2\% of colorectal carcinoma (CRC) patients experience isolated metachronous para-aortic lymph node (PALN) recurrence (MPR) after curative surgical excision of the primary tumor. ${ }^{1}$ Synchronous PALN metastasis (SPM) is considered a stage-IV disease., ${ }^{2,3}$

Previous studies ${ }^{4}$ have established the roles of surgical resection and chemotherapy (CTx) in the management of isolated liver and lung cancer recurrences, which led to improvements in patient prognosis.

The relative rarity of MPR and SPM leads to limited number of studies on patient management, and no treatment guidelines have been established to date. ${ }^{5}$

Curative resection was found to be beneficial for CRC patients with isolated MPR. ${ }^{5}$ One study ${ }^{6}$ reported that the outcomes of CRC patients after chemoradiotherapy (CRT) were similar to those of the patients who underwent surgical resection.

Moreover, MPR resectiombelow the renal veins can be safely performed and improve prognosis in comparison to non-surgical resection. ${ }^{7}$

Recent studies ${ }^{9,10}$ have updated the prognostic predictive parameters for the successful surgical management of SPM, including R0 resection, histological type, number of PALNs, presence of metastatic lateral pelvic lymph node, distant metastases, and preoperative levels of carcinoembryonic antigen (CEA).

No clear predictive parameters for the successful surgical management of MPR have been established to date.

Additionally, no previous studies have assessed the prognostic parameters and role of surgical resection in cases of SPM and MPR in CRC patients.

In the present study, we aimed to assess the prognostic, predictive roles, and long-term outcomes of different management strategies for SPM and MPR in CRC patients-PALN dissection (PALND) and CRT-to establish the best management strategy.

\section{Materials and Methods}

The present prospective cohort study included 60 consecutive CRC patients: 35 patients clinically or radiologically diagnosed with isolated MPR,and 25 patients clinically or radiologically diagnosed with isolated SPM who underwent curative R0 resection (no gross or microscopic residual tumor after surgical excision) from January 2014 to December 2019 at the General Surgery Department, Faculty of Medicine, Zagazig University Hospitals, Zagazig, Egypt.The PALNs are the lymph nodes around the abdominal aorta and inferior vena cava, and recurrence in them and extending laterally to the psoas major muscles, cranially to the diaphragm, and caudally to the common iliac vessels was confirmed by computed tomography (CT), magnetic resonance imaging (MRI), and positron emission tomography (PET) findings, as well as by the high serum levels of CEA.

We performed PALND in 10 (40\%) patients with SPM and in $15(42.9 \%)$ patients with MPR. All remaining patients in both groups underwent CRT without further surgical intervention. During the follow-up (median: 37 months; range: 10 to 55 months), we compared the patients who underwent surgery and those who underwent CRT.

\section{Exclusion Criteria}

Patients with incompletely resected tumors who could not undergo R0 resection, patients with multiple PALNs on both sides of the aorta, and patients with multiple recurrences invading the celiac or superior mesenteric artery were excluded.

After the application of the inclusion and exclusion criteria, 25 patients with SPM and 35 patients with MPR after curative R0 resection were included in the present study.

We collected and reviewed the medical charts, and identified the clinical findings, the pathological characteristics of the tumor, and the survival outcomes of the patients. The perioperative characteristics of patients with PALN recurrence and their management were reported.

The study protocol was approved by the Institutional Review Board (IRB) of the Faculty of Medicine at Zagazig University (IRB No. 2015-1458), and written informed consent was obtained from the patients.

The resectability of the PALNs was evaluated by a multidisciplinary team which included colorectal surgeons, radiologists, pathologists, and oncologists. We divided the location of the recurrent nodes into three classes; left or right sides of the aorta, above the renal vessels, and below the renal vessels.

\section{Treatment of Patients with MPR}

The management of MPR included surgical resection with curative intent, which included wide excision of the involved lymph node in addition to any invaded adjacent tissue, and part of the surrounding normal tissue, to reach free safety resection margins. After surgical resection, patients with histopathological confirmation of MPR underwent adjuvant CTx and CRT. A standard total radiation dose of $48 \mathrm{~Gy}$ to $55.4 \mathrm{~Gy}$ in fractions of $25 \mathrm{~Gy}$ to $31 \mathrm{~Gy}$ was applied.

Patients with histopathological confirmation of absence of MPR received no further treatment. 


\section{Treatment of Patients with SPM}

Patients with SPM were submitted to surgical resection of the CRC in addition to PALND according to the following parameters: clinical and radiological evidence of metastatic PALN located below the renal vein; with expected negative R0 resection. We perfomed metastasectomy for most patients after resection of the primary tumor and second stage metastasectomy, as metachronous hepatectomy in some patients

The PALND procedure included dissection of lymphatic and connective tissues around the abdominal aorta and inferior vena cava between the left renal vein and iliac artery bifurcation.

\section{Follow-up}

After surgical dissection, we followed up all patients every three months to assess tumor markers, and they were submitted to chest and abdominal CTs every six months. All patients with rectal cancer underwent a yearly colonoscopy, and those with colon cancer underwent it every other year, to detect early local recurrence.

We defined local recurrence as recurrence inside the pelvic cavity in cases of rectal cancer, and as recurrence around the tumor area in cases of colon cancer.

\section{Statistical Analysis}

The statistical analysis of the collected data was performed using the Statistical Package for the Social Sciences (IBM SPSS Statistics for Windows, IBM Corp., Armonk, NY, US) software, version 24.0. The Chi-squared test $\left(\mathrm{X}^{2}\right)$ and the Fisher exact were used to calculate the differences among the qualitative variables, and the Mann Whitney test, to calculate the difference among the quantitative variables. Values of $p<$ 0.05 indicate statistically significant differences, and values $<0.001$ indicate highly-significant differences. The Kaplan and Meier method was used to detect the overall survival (OS) and the recurrence-free survival (RFS) rates, and the logrank test was used to compare the survival curves. The time from the date of the diagnosis until the date of death or of the last follow-up is the OS, and the RFS is time from the date of complete response (CR) to the therapy until the date of relapse.

We used the Cox proportional hazards model for the univariate analysis, and statistically significant variables were included in it.

\section{Results}

\section{Clinicopathological and demographic characteristics of all CRC patients (- Tables 1 and 2)}

We included 60 CRC patients, 40 men (66.7\%) and 20 woman (33.3\%), with a median age of 50 years (range: 30 to 68 years). Conventional adenocarcinoma of the colon was diagnosed in 50 patients (83.3\%), right hemicolectomy was performed $50 \%$ of the patients, left hemicolectomy, in $26.7 \%$, anterior resection, in $8.3 \%$, and abdominoperineal resection, in $15 \%$ of the patients. The median size of the largest PALNs was $15 \mathrm{~mm}$ (range: 12 to $20 \mathrm{~mm}$ ). A total of $50 \%$ of the patients underwent preoperative CRT, and $80 \%$ were submitted to postoperative
CRT. Complete response to therapy was observed in $65 \%$ of the patients, and the OS rate was of 50\% (- Figure 1 A,B).

Regarding the demographic, clinical, and pathological parameters, we found no statistically significant differences between patients diagnosed with SPM or MPR, or between patients who underwent PALND and those who did not.

Patients with MPR had better RFS rates than those with SPM (23.6\% versus $12.1 \%$ respectively; $p=0.014$ ), while patients with SPM had better OS rates than those with MPR (60\% versus $12.5 \%$ respecrtively; $p=\mathbf{0 . 0 2 2}$ ) ( - Tables 3 and 4; -Figures 1 C,D).

\section{Characteristics of PALN Recurrence and PALND in Patients with Metachronus PALN Metastases}

A total of 15 MPR patients (42.9\%) underwent PALND. After the pathological examination $20 \%$ of these patients were diagnosed with chronic granulomatous inflammation and fibrosis; they did not undergo any further treatment, and were followed up.

Following resection, the median size of the largest PALNs was $15 \mathrm{~mm}$ (range: 12 to $20 \mathrm{~mm}$ ). Of the 20 patients (57.1\%) treated with CTx alone, 10 were treated with folinic acid, fluorouracil, and irinotecan (FOLFIRI), 2, with folinic acid, fluorouracil, and oxaliplatin (FOLFOX), 4, with capecitabine and oxaliplatin (XELOX), 1, with folinic acid and fluorouracil (LF), 2, with oral capecitabine, and $2 \%$, with targeted agents alone (pembrolizumab and avastin).

We found no significant differences in terms of demographic and clinical characteristics between MPR patients who did and did not undergo PALND.

\section{Survival Outcomes and Factors Related to the Prognosis of MPR Patients Submitted to PALND}

The 15 MPR patients who underwent PALND, had significantly better OS and RFS rates. The multivariate analysis showed that the factors associated with favorable survival were primary tumor in a less advanced stage, performance of CTx, and PALND.

\section{Characteristics of PALND in SPM Patients}

A total of 10 SPM patients (40\%) underwent PALND. After the pathological examination, 1 of these patients was diagnosed with lymphadenitis, but underwent no further treatment, and was followed up.

Following resection, the median size of the largest PALNs was $15 \mathrm{~mm}$ (range: 12 to $20 \mathrm{~mm}$ ). Of the 15 patients (60\%) treated with CTx alone, 8 were treated with FOLFIRI, 2, with FOLFOX, 2, with XELOX, 1, with LF, 2, with oral capecitabine, and 1 , with targeted agents alone (pembrolizumab and avastin).

We found no significant differences in terms of demographic and clinical characteristics between SPM patients who did and did not undergo PALND.

\section{Survival Outcomes and Factors Related to the Prognosis of SPM Patients Submitted to of PALND}

The 10 SPM patients who under went PALND had significantly better OS and RFS rates. The multivariate analysis showed that the factors associated with favorable survival 
Table 1 Clinicopathological features and outcomes of all patients, and of those with SPM and MPR

\begin{tabular}{|c|c|c|c|c|c|c|c|c|}
\hline \multirow[t]{3}{*}{ Variable } & & \multirow{2}{*}{\multicolumn{2}{|c|}{$\begin{array}{l}\text { SPM } \\
N=25\end{array}$}} & \multirow{2}{*}{\multicolumn{2}{|c|}{$\begin{array}{l}\text { MPR } \\
N=35\end{array}$}} & \multirow{2}{*}{\multicolumn{2}{|c|}{$\begin{array}{l}\text { Total } \\
\mathrm{N}=60\end{array}$}} & \multirow[t]{3}{*}{$p$-value } \\
\hline & & & & & & & & \\
\hline & & $\mathrm{n}$ & $\%$ & $\mathrm{n}$ & $\%$ & $\mathrm{n}$ & $\%$ & \\
\hline \multicolumn{2}{|l|}{ Mean age in years (range) } & \multicolumn{2}{|c|}{$50(30-65)$} & \multicolumn{2}{|c|}{$50(32-68)$} & \multicolumn{2}{|c|}{$50(30-68)$} & 0.976 \\
\hline \multirow[t]{2}{*}{ Histopathological subtype } & $\begin{array}{l}\text { Conventional } \\
\text { adenocarcinoma }\end{array}$ & 22 & 88.0 & 28 & 80.0 & 50 & 83.3 & \multirow[t]{2}{*}{0.412} \\
\hline & Mucoid carcinoma & 3 & 12.0 & 7 & 20.0 & 10 & 16.7 & \\
\hline \multirow[t]{4}{*}{ Site of the primary tumor } & Ascending colon & 7 & 28.0 & 20 & 57.1 & 27 & 45.0 & \multirow[t]{4}{*}{0.038} \\
\hline & Rectosigmoid & 10 & 40.0 & 4 & 11.4 & 14 & 23.3 & \\
\hline & Descending colon & 3 & 12.0 & 6 & 17.1 & 9 & 15.0 & \\
\hline & Transverse colon & 5 & 20.0 & 5 & 14.3 & 10 & 16.7 & \\
\hline \multirow[t]{4}{*}{ Duke stage } & $A$ & 2 & 8.0 & 9 & 25.7 & 11 & 18.3 & \multirow[t]{4}{*}{$<0.001$} \\
\hline & $\mathrm{B}$ & 11 & 44.0 & 0 & 0.0 & 11 & 18.3 & \\
\hline & $\mathrm{C}$ & 12 & 48.0 & 13 & 37.1 & 25 & 41.7 & \\
\hline & $\mathrm{D}$ & 0 & 0.0 & 13 & 37.1 & 13 & 21.7 & \\
\hline \multirow[t]{4}{*}{ Type of primary operation } & Right hemicolectomy & 10 & 40.0 & 20 & 57.1 & 30 & 50.0 & \multirow[t]{4}{*}{0.075} \\
\hline & Left hemicolectomy & 5 & 20.0 & 11 & 31.4 & 16 & 26.7 & \\
\hline & Anterior resection & 4 & 16.0 & 1 & 2.9 & 5 & 8.3 & \\
\hline & Abdominoperineal resection & 6 & 24.0 & 3 & 8.6 & 9 & 15.0 & \\
\hline \multicolumn{2}{|c|}{ Mean size of largest PALN in millimeters (range) } & \multicolumn{2}{|c|}{$15(12-20)$} & \multicolumn{2}{|c|}{$15(12-20)$} & \multicolumn{2}{|c|}{$15(12-20)$} & 0.655 \\
\hline \multirow[t]{2}{*}{ PALND } & No & 15 & 60.0 & 20 & 57.1 & 35 & 58.3 & \multirow[t]{2}{*}{0.825} \\
\hline & Yes & 10 & 40.0 & 15 & 42.9 & 25 & 41.7 & \\
\hline \multirow[t]{2}{*}{ Preoperative chemoradiotherapy } & No & 13 & 52.0 & 17 & 48.6 & 30 & 50.0 & \multirow[t]{2}{*}{0.793} \\
\hline & Yes & 12 & 48.0 & 18 & 51.4 & 30 & 50.0 & \\
\hline \multirow[t]{3}{*}{ Postoperative chemoradiotherapy } & No & 5 & 20.0 & 7 & 20.0 & 12 & 20.0 & \multirow[t]{3}{*}{$>0.999$} \\
\hline & Yes & 20 & 80.0 & 28 & 80.0 & 48 & 80.0 & \\
\hline & Yes -distant metastasis & 1 & 14.3 & 6 & 46.2 & 7 & 35.0 & \\
\hline
\end{tabular}

Abbreviations: MPR, metachronous para-aortic lymph node recurrence; PALN, para-aortic lymph node; PALND, para-aortic lymph node dissection; SPM, synchronous para-aortic lymph node metastasis.

were primary tumor in a less advanced stage, performance of CTx, and PALND.

The univariate Cox regression analyses showed that SPM and PALNs with the largest sizes were the most significant predictors of RFS $(p=0.04)$., and, in the multivariate analysis, the most significant predictor of RFS was preoperative CRT $(p<0.001)$ ( - Table 5 ).

The univariate Cox regression analyses showed that SPM and the stage in the Duke classificatioon were the most significant predictors of OS ( $p=0.029$ and 0.031 respectively), and in the multivariate analysis, the most significant predictors of OS was preoperative CRT $(p=0.003)$ ( - Table 6 ).

\section{Discussion}

In the current study, we showed that the prognosis and the survival rates of CRC patients with SPM or MPR who underwent PALND was better than that of patients who did not undergo surgical excision. Our findings are in line with those of previous studies. ${ }^{1,8,9}$ Our study was similar to the one by
Ushigome et al., ${ }^{9}$ which was also restricted to patients who underwent $\mathrm{R} 0$ resection of the primary tumor.

We showed that the 5-year OS and RFS rates of the SPM patients who underwent PALND were better than those of patients with general stage-IV tumors; thus, PALND was found to improve patient prognosis. This finding is similar to those of previous reports. ${ }^{7,10-12}$

Ushigome et al. ${ }^{9}$ showed that PALND is associated with favorable survival, but it was also associated with early unresectable recurrences. This might be due to the fact that the CRC patients who developed unresectable recurrences and died within one year after PALND were primarily found to have no indication for the procedure. Thus, accurate diagnosis of patients with CRC who should undergo PALND is essential to improve prognosis.

All of these results collectively provide further evidence for the effectiveness of surgical management.

Surgical resection for isolated MPR or SPM has many advantages, as it enables an accurate histopathological confirmation of recurrence or metastasis, particularly in cases 
Table 2 Clinicopathological features and outcomes of patients who did and did not undergo PALND

\begin{tabular}{|c|c|c|c|c|c|c|c|c|}
\hline \multirow{3}{*}{\multicolumn{2}{|c|}{ Variable }} & \multicolumn{4}{|l|}{ PALND } & \multirow{2}{*}{\multicolumn{2}{|c|}{$\begin{array}{l}\text { Total } \\
\mathrm{N}=60\end{array}$}} & \multirow[t]{3}{*}{$p$-value } \\
\hline & & \multicolumn{2}{|l|}{$\begin{array}{l}\text { Yes } \\
\mathrm{N}=35\end{array}$} & \multicolumn{2}{|l|}{$\begin{array}{l}\text { No } \\
N=25\end{array}$} & & & \\
\hline & & $\mathrm{n}$ & $\%$ & $\mathbf{n}$ & $\%$ & $\mathrm{n}$ & $\%$ & \\
\hline \multicolumn{2}{|c|}{ Mean age in years (range) } & $\begin{array}{l}50 \\
(30-68)\end{array}$ & & $\begin{array}{l}54 \\
(32-67)\end{array}$ & & $\begin{array}{l}50 \\
(30-68)\end{array}$ & & 0.192 \\
\hline \multirow[t]{2}{*}{ Gender } & Female & 12 & 34.3 & 8 & 32.0 & 20 & 33.3 & 0.853 \\
\hline & Male & 23 & 65.7 & 17 & 68.0 & 40 & 66.7 & \\
\hline \multirow{2}{*}{$\begin{array}{l}\text { Histopathological } \\
\text { subtype }\end{array}$} & Conventional adeno carcinoma & 29 & 82.9 & 21 & 84.0 & 50 & 83.3 & 0.907 \\
\hline & Mucoid carcinoma & 6 & 17.1 & 4 & 16.0 & 10 & 16.7 & \\
\hline \multirow{4}{*}{$\begin{array}{l}\text { Site of the primary } \\
\text { tumor }\end{array}$} & Ascending colon & 14 & 40.0 & 13 & 52.0 & 27 & 45.0 & 0.237 \\
\hline & Rectosigmoid & 10 & 28.6 & 4 & 16.0 & 14 & 23.3 & \\
\hline & Descending colon & 7 & 20.0 & 2 & 8.0 & 9 & 15.0 & \\
\hline & Transverse colon & 4 & 11.4 & 6 & 24.0 & 10 & 16.7 & \\
\hline \multirow[t]{4}{*}{ Duke stage } & $A$ & 6 & 17.1 & 5 & 20.0 & 11 & 18.3 & 0.001 \\
\hline & $\mathrm{B}$ & 11 & 31.4 & 0 & 0.0 & 11 & 18.3 & \\
\hline & C & 8 & 22.9 & 17 & 68.0 & 25 & 41.7 & \\
\hline & $\mathrm{D}$ & 10 & 28.6 & 3 & 12.0 & 13 & 21.7 & \\
\hline \multirow[t]{2}{*}{ PALN } & Synchronous metastasis & 15 & 42.9 & 10 & 40.0 & 25 & 41.7 & 0.825 \\
\hline & Meta-chronous recurrence & 20 & 57.1 & 15 & 60.0 & 35 & 58.3 & \\
\hline \multirow{4}{*}{$\begin{array}{l}\text { Type of primary } \\
\text { operation }\end{array}$} & Right hemicolectomy & 14 & 40.0 & 16 & 64.0 & 30 & 50.0 & 0.306 \\
\hline & Left hemicolectomy & 11 & 31.4 & 5 & 20.0 & 16 & 26.7 & \\
\hline & Anterior resection & 4 & 11.4 & 1 & 4.0 & 5 & 8.3 & \\
\hline & Abdominoperineal resection & 6 & 17.1 & 3 & 12.0 & 9 & 15.0 & \\
\hline \multicolumn{2}{|c|}{ Mean size of largest PALN in millimeters (range) } & $\begin{array}{l}14 \\
(12-15)\end{array}$ & & $\begin{array}{l}18 \\
(17-20)\end{array}$ & & $\begin{array}{l}15 \\
(12-20)\end{array}$ & & $<0.001$ \\
\hline \multirow{4}{*}{$\begin{array}{l}\text { Response to } \\
\text { treatment }\end{array}$} & PD & 4 & 11.4 & 2 & 8.0 & 6 & 10.0 & 0.962 \\
\hline & SD & 4 & 11.4 & 3 & 12.0 & 7 & 11.7 & \\
\hline & PR & 5 & 14.3 & 3 & 12.0 & 8 & 13.3 & \\
\hline & CR & 22 & 62.9 & 17 & 68.0 & 39 & 65.0 & \\
\hline \multirow{2}{*}{$\begin{array}{l}\text { Preoperative } \\
\text { chemoradiotherapy }\end{array}$} & No & 16 & 45.7 & 14 & 56.0 & 30 & 50.0 & 0.432 \\
\hline & Yes & 19 & 54.3 & 11 & 44.0 & 30 & 50.0 & \\
\hline \multirow{2}{*}{$\begin{array}{l}\text { Postoperative } \\
\text { chemoradiotherapy }\end{array}$} & No & 6 & 17.1 & 6 & 24.0 & 12 & 20.0 & 0.513 \\
\hline & Yes & 29 & 82.9 & 19 & 76.0 & 48 & 80.0 & \\
\hline \multirow[t]{2}{*}{ PALN } & Synchronous metastasis & 15 & 42.9 & 10 & 40.0 & 25 & 41.7 & 0.825 \\
\hline & Metachronous recurrence & 20 & 57.1 & 15 & 60.0 & 35 & 58.3 & \\
\hline
\end{tabular}

Abbreviations: CR, complete response; PD, progressive disease; PALN, para-aortic lymph node; PALND, para-aortic lymph node dissection; PR, partial response; SD, stable disease.

which might difficult to diagnose by imaging alone. Thus, it also enables the provision of a better therapy, avoids unneeded treatment strategies, and leads to an improvement in patient outcomes and survival, ${ }^{12}$ as shown in the present study. These results were similar to those of the study by Kim et al., ${ }^{1}$ in which three patients who underwent PALND were histopathologically confirmed to be negative for malignant recurrence. These patients avoided additional unnecessary adjuvant therapy, and only underwent regular follow-up to detect possible recurrences later on.
Moreover, 20\% of the patients with misdiagnosis of recurrence who did not undergo surgical resection may unnecessarily undergo chemotherapy.

The rate of misdiagnosis of recurrence was of about $20 \%$, which was similar to the rates found in previous studies. ${ }^{13-16}$

Regarding the response to therapy in the present study, it was better among the patients who underwent PALND than among those who did not. Moreover, disease progression and further development of distant metastases to the liver, lung, 

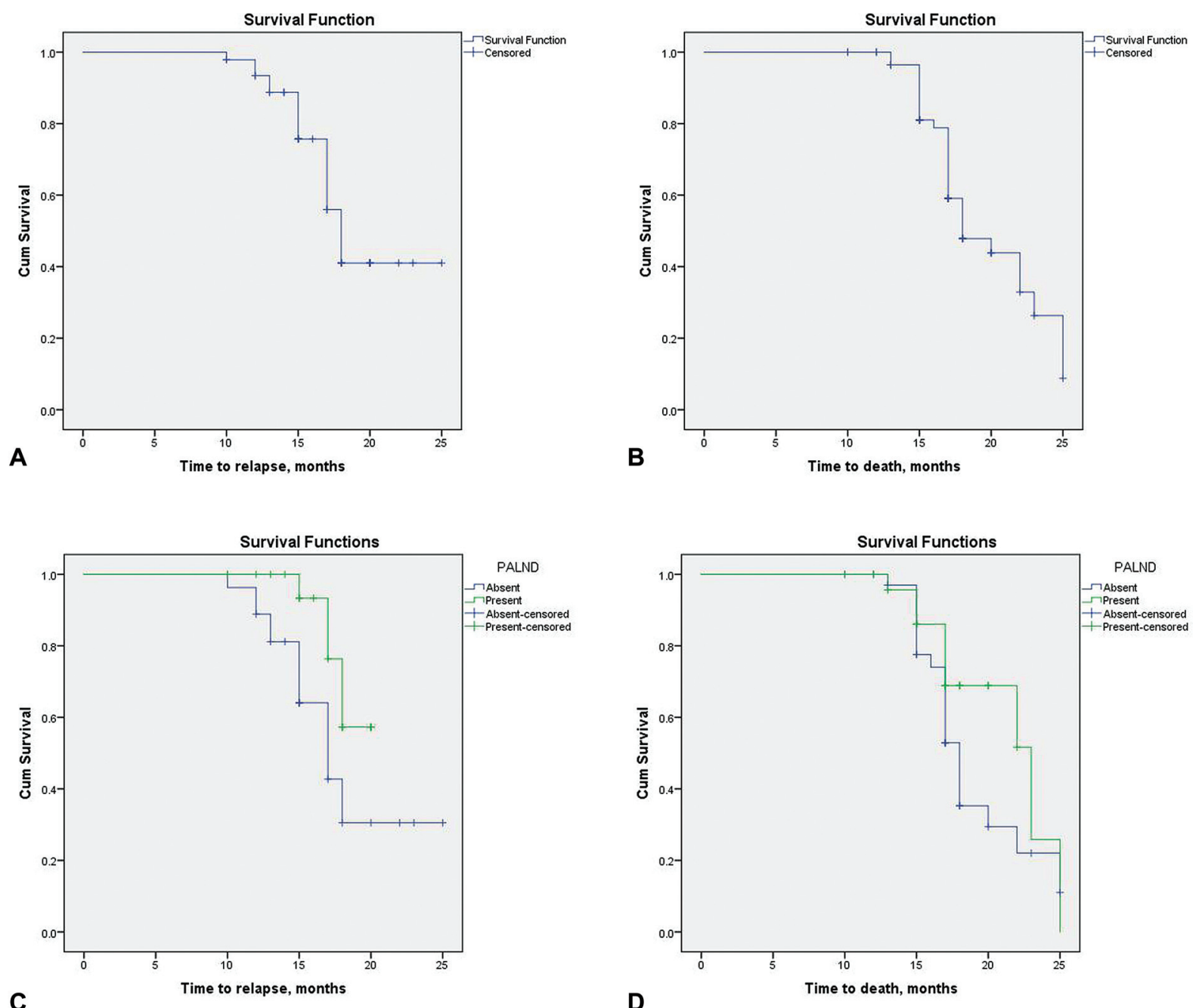

Fig. 1 (A) Kaplan-Meier survival curves illustrating the RFS time differences in all the studied CRC patients. (B) Kaplan-Meier survival curves illustrating the OS time differences in all the studied CRC patients (C) Kaplan-Meier survival curves illustrating RSF time differences in patients submitted to PALND. (D) Kaplan-Meier survival curves illustrating OS time differences in patients submitted to PALND.

Table 3 Recurrence and survival of patients who did and did not undergo para-aortic lymph node dissection (PALND)

\begin{tabular}{|c|c|c|c|c|c|c|c|c|}
\hline \multirow[t]{3}{*}{ Variable } & & \multicolumn{4}{|c|}{ PALND } & \multirow{2}{*}{\multicolumn{2}{|c|}{ Total }} & \multirow[t]{3}{*}{ p-value } \\
\hline & & \multicolumn{2}{|c|}{$\begin{array}{l}\text { No } \\
N=35\end{array}$} & \multicolumn{2}{|c|}{$\begin{array}{l}\text { Yes } \\
N=25\end{array}$} & & & \\
\hline & & $\mathbf{n}$ & $\%$ & $\mathbf{n}$ & $\%$ & $\mathbf{n}$ & $\%$ & \\
\hline \multirow[t]{2}{*}{ Recurrence pattern after PALND } & Local & 8 & $34.8 \%$ & 5 & $50.0 \%$ & 13 & $39.4 \%$ & 0.411 \\
\hline & Distant & 15 & $65.2 \%$ & 5 & $50.0 \%$ & 20 & $60.6 \%$ & \\
\hline \multirow[t]{2}{*}{ Death } & No & 14 & $40.0 \%$ & 16 & $64.0 \%$ & 30 & $50.0 \%$ & 0.047 \\
\hline & Yes & 21 & $60.0 \%$ & 9 & $36.0 \%$ & 30 & $50.0 \%$ & \\
\hline \multirow[t]{2}{*}{ Relapse* } & No & 12 & $44.4 \%$ & 15 & $75.0 \%$ & 27 & $57.4 \%$ & 0.036 \\
\hline & Yes & 15 & $55.6 \%$ & 5 & $25.0 \%$ & 20 & $42.6 \%$ & \\
\hline
\end{tabular}

Note: * Calculated from patients with documented response to therapy. 
Table 4 Survival rates of patients who did and did not undergo para-aortic lymph nodes dissection (PALND)

\begin{tabular}{|c|c|c|c|c|c|c|c|c|c|c|}
\hline \multirow[t]{3}{*}{ PALND } & \multirow[t]{3}{*}{ Total } & \multirow{3}{*}{$\begin{array}{l}\text { Number } \\
\text { of Events }\end{array}$} & \multirow{3}{*}{\multicolumn{2}{|c|}{ Censored }} & \multicolumn{4}{|c|}{ Survival time in months } & \multirow{3}{*}{$\begin{array}{l}\text { Survival } \\
\text { rate }\end{array}$} & \multirow[t]{3}{*}{$p$-value } \\
\hline & & & & & \multicolumn{2}{|l|}{ Mean } & \multicolumn{2}{|l|}{ Median } & & \\
\hline & & & & & $\begin{array}{l}\text { Estimate } \pm \\
\text { standard } \\
\text { error }\end{array}$ & $\begin{array}{l}95 \% \\
\text { confidence } \\
\text { interval }\end{array}$ & $\begin{array}{l}\text { Estimate } \pm \\
\text { standard } \\
\text { error }\end{array}$ & $\begin{array}{l}95 \% \\
\text { confidence } \\
\text { interval }\end{array}$ & & \\
\hline \multicolumn{11}{|c|}{ Overall survival } \\
\hline No & 35 & 21 & 14 & $40.0 \%$ & $18.9 \pm 0.8$ & $17.4-20.4$ & $18.0 \pm 0.5$ & $17.0-19.0$ & $11.0 \%$ & \multirow[t]{2}{*}{0.049} \\
\hline Yes & 25 & 9 & 16 & $64.0 \%$ & $21.1 \pm 1.0$ & $19.1-23.1$ & $23.0 \pm 2.8$ & $17.5-28.5$ & $0.0 \%$ & \\
\hline Total & 60 & 30 & 30 & $50.0 \%$ & $19.8 \pm 0.6$ & $18.6-21.0$ & $18.0 \pm 1.5$ & $15.0-21.0$ & $41.0 \%$ & \\
\hline \multicolumn{11}{|c|}{$\begin{array}{l}\text { Relapse-free } \\
\text { survival }\end{array}$} \\
\hline No & 27 & 15 & 12 & $44.4 \%$ & $18.3 \pm 1.0$ & $16.2-20.3$ & $17.0 \pm 1.0$ & $15.0-19.0$ & $30.5 \%$ & 0.036 \\
\hline Yes & 20 & 5 & 15 & $75.0 \%$ & $18.8 \pm 0.4$ & $17.9-19.6$ & Not reached & & $57.3 \%$ & \\
\hline Total & 47 & 20 & 27 & $57.4 \%$ & $19.6 \pm 0.8$ & $18.0-21.2$ & $18.0 \pm 0.6$ & $16.8-19.2$ & $8.8 \%$ & \\
\hline
\end{tabular}

Table 5 Univariate and multivariate Cox regression analyses of the rate of relapse-free survival

\begin{tabular}{|c|c|c|c|c|}
\hline \multirow[t]{3}{*}{ Covariate } & \multicolumn{4}{|c|}{ Relapse-free survival } \\
\hline & \multicolumn{2}{|c|}{ Univariate } & \multicolumn{2}{|c|}{ Multivariate } \\
\hline & $p$-value & $\begin{array}{l}\text { Hazard ratio } \\
\text { ( } 95 \% \text { confidence } \\
\text { interval) }\end{array}$ & $p$-value & $\begin{array}{l}\text { Hazard rastio } \\
\text { ( } 95 \% \text { confidence } \\
\text { interval) }\end{array}$ \\
\hline Age (years) & 0.87 & $1.00(0.95-1.04)$ & & \\
\hline Gender & 0.033 & $1.63(1.04-2.56)$ & 0.034 & $1.62(1.04-2.52)$ \\
\hline Histopathological subtype & 0.339 & $0.49(0.11-2.12)$ & & \\
\hline \multicolumn{5}{|l|}{ Site of the primary tumor } \\
\hline Ascending colon & 0.824 & $0.86(0.23-3.25)$ & & \\
\hline Rectosigmoid & 0.948 & $1.05(0.25-4.39)$ & & \\
\hline Descending colon & 0.087 & $3.79(0.82-17.40)$ & & \\
\hline \multicolumn{5}{|l|}{ Duke stage } \\
\hline$A$ & 0.375 & $1.89(0.46-7.70)$ & & \\
\hline$B$ & 0.667 & $0.75(0.20-2.83)$ & & \\
\hline C & 0.16 & $0.41(0.12-1.42)$ & & \\
\hline SPM and MPR & 0.04 & $2.72(1.05-7.10)$ & & \\
\hline Size of the largest PALN (mm) & 0.043 & $0.83(0.68-0.99)$ & 0.145 & $0.86(0.70-1.05)$ \\
\hline \multicolumn{5}{|l|}{ Type of primary operation } \\
\hline Right hemicolectomy & 0.653 & $1.43(0.30-6.72)$ & & \\
\hline Left hemi-colectomy & 0.08 & $4.11(0.85-20.00)$ & & \\
\hline Anterior resection & 0.081 & $4.94(0.82-29.71)$ & & \\
\hline PALND & 0.062 & $0.38(0.14-1.05)$ & & \\
\hline Preoperative chemoradiotherapy & $<0.001$ & $7.32(2.43-21.99)$ & 0.001 & $6.16(2.02-18.78)$ \\
\hline Postoperative chemoradiotherapy & 0.108 & $32.28(0.46-2240.74)$ & & \\
\hline
\end{tabular}

Abbreviations: MPR, metachronous para-aortic lymph node recurrence; PALN, para-aortic lymph node; PALND, para-aortic lymph node dissection; SPM, synchronous para-aortic lymph node metastasis. 
Table 6 Univariate and multivariate Cox regression analyses of the overall survival rate

\begin{tabular}{|c|c|c|c|c|}
\hline \multirow[t]{3}{*}{ Covariate } & \multicolumn{4}{|c|}{ Overall survival } \\
\hline & \multicolumn{2}{|c|}{ Univariate } & \multicolumn{2}{|c|}{ Multivariate } \\
\hline & $p$-value & $\begin{array}{l}\text { Hazard ratio } \\
\text { ( } 95 \% \text { confidence } \\
\text { interval) }\end{array}$ & $p$-value & $\begin{array}{l}\text { Hazard ratio } \\
\text { ( } 95 \% \text { confidence } \\
\text { interval) }\end{array}$ \\
\hline Age (years) & 0.199 & $1.03(0.99-1.07)$ & & \\
\hline Gender & 0.792 & $0.88(0.35-2.23)$ & & \\
\hline Histopathological subtype & 0.978 & $1.01(0.41-2.52)$ & & \\
\hline \multicolumn{5}{|l|}{ Site of the primary tumor } \\
\hline Ascending colon & 0.458 & $1.52(0.50-4.63)$ & & \\
\hline Recto-sigmoid & 0.896 & $1.09(0.31-3.87)$ & & \\
\hline Descending colon & 0.076 & $3.39(0.88-13.03)$ & & \\
\hline \multicolumn{5}{|l|}{ Duke stage } \\
\hline$A$ & 0.998 & $1.00(0.30-3.32)$ & 0.959 & $1.04(0.25-4.32)$ \\
\hline$B$ & 0.173 & $0.47(0.16-1.39)$ & 0.961 & $1.04(0.23-4.66)$ \\
\hline$C$ & 0.031 & $0.35(0.13-0.91)$ & 0.229 & $0.52(0.18-1.51)$ \\
\hline SPM and MPR & 0.029 & $2.61(1.10-6.17)$ & 0.079 & $2.48(0.90-6.82)$ \\
\hline Size of the largest PALN (mm) & 0.211 & $0.91(0.79-1.05)$ & & \\
\hline \multicolumn{5}{|l|}{ Type of primary operation } \\
\hline Right hemicolectomy & 0.506 & $1.45(0.48-4.38)$ & & \\
\hline Left hemicolectomy & 0.264 & 1.99 (0.59-6.67) & & \\
\hline Anterior resection & 0.631 & $1.52(0.27-8.44)$ & & \\
\hline PALND & 0.204 & $1.66(0.76-3.63)$ & & \\
\hline Preoperative chemoradiotherapy & 0.002 & $0.21(0.08-0.57)$ & 0.003 & $0.01(0.00-0.23)$ \\
\hline Postoperative chemoradiotherapy & 0.037 & $4.65(1.10-19.62)$ & 0.205 & $2.72(0.58-12.76$ \\
\hline Relapse & 0.011 & $3.37(1.32-8.63)$ & 0.004 & $0.01(0.001-0.26$ \\
\hline Response to treatment & $<0.001$ & $0.54(0.39-0.75)$ & 0.023 & $0.59(0.38-0.93)$ \\
\hline
\end{tabular}

Abbreviations: MPR, metachronous para-aortic lymph node recurrence; PALN, para-aortic lymph node; PALND, para-aortic lymph node dissection; SPM, synchronous para-aortic lymph node metastasis.

and bone was higher among patients who did not undergo surgical excision.

Additionally, in patients who do not undergo PALND, metastasis to distant organs may result from unresected PALN metastasis. ${ }^{9}$

In the present study, the stage of the primary tumor was the most important prognostic factor for patient survival, and it was similar in patients who did and did not undergo resection.

\section{Conclusions}

We showed that PALND in cases of CRC patients with SPM and MPR previously submitted to R0 resection was associated with favorable outcomes and better patient survival.

The accurate histopathological diagnosis of SPM and PMR can alter treatment strategies.

\section{Strengths of the Present Study}

In the present report, we have overcome certain weaknesses of previous studies: ${ }^{1,12}$ first, the present was a prospective study, which enabled better data collection and analysis to reach accurate results; second, we included patients with SPM and MPR to verify the role of PALND whether it was done during resection of the primary tumor or resection of isolated PALN recurrence; third, we compared patients who underwent PALND and those who only underwent CRT; and, fourth, the present study was performed by a multidisplinary team composed of gastrointestinal oncologists, oncologic surgeons, and radiologists, which made the management strategies more accurate.

\section{Limitations of the Study}

Among the limitations of the present study, we can mention the fact that it was performed in a single center, the relatively small sample, and the relatively short follow-up.

\section{Recommendations}

Larger prospective studies comparing patients submitted to different management strategies and with a longer follow-up are needed to determine the best treatment. 


\section{Conflict of Interest}

The authors have no conflict of interests to declare.

\section{References}

1 Kim YI, Park IJ, Park JH, et al. Management of isolated para-aortic lymph node recurrence after surgery for colorectal cancer. Ann Surg Treat Res 2020;98(03):130-138

2 Patriarca S, Ferretti S, Zanetti R. TNM Classification of malignant tumours Eighth edition: which news? Epidemiol Prev 2017;41 (02):140-3

3 Hashiguchi Y, Muro K, Saito Y, et al; Japanese Society for Cancer of the Colon and Rectum. Japanese Society for Cancer of the Colon and Rectum (JSCCR) guidelines 2019 for the treatment of colorectal cancer. Int J Clin Oncol 2020;25(01):1-42

4 Bellier J, De Wolf J, Hebbar M, et al. Repeated resections of hepatic and pulmonary metastases from colorectal cancer provide longterm survival. World J Surg 2018;42(04):1171-1179

5 Takeshima K, Yamafuji K, Asami A, et al. Successful resection of isolated paraaortic lymph node recurrence from advan ced sigmoid colon cancer following 156 courses of FOLFIRI regimen. Case Rep Surg 2016;2016:4548798

6 Yeo SG, Kim DY, Kim TH, et al. Curative chemoradiotherapy for isolated retroperitoneal lymph node recurrence of colorectal cancer. Radiother Oncol 2010;97(02):307-311

7 Bae SU, Han YD, Cho MS, et al. Oncologic outcomes of colon cancer patients with extraregional lymph node metastasis: comparison of isolated paraaortic lymph node metastasis with resectable liver metastasis. Ann Surg Oncol 2016;23(05):1562-1568
8 Min BS, Kim NK, Sohn SK, Cho CH, Lee KY, Baik SH. Isolated paraaortic lymph-node recurrence after the curative resection of colorectal carcinoma. J Surg Oncol 2008;97(02):136-140

9 Ushigome H, Yasui M, Ohue M, et al. The treatment strategy of R0 resection in colorectal cancer with synchronous para-aortic lymph node metastasis. World J Surg Oncol 2020;18(01):229

10 Sahara K, Watanabe J, Ishibe A, et al. Long-term outcome and prognostic factors for patients with para-aortic lymph node dissection in left-sided colorectal cancer. Int J Colorectal Dis 2019;34(06):1121-1129

11 Nakai N, Yamaguchi T, Kinugasa Y, et al. Long-term outcomes after resection of para-aortic lymph node metastasis from left-sided colon and rectal cancer. Int J Colorectal Dis 2017;32(07):999-1007

12 Yamada K, Tsukamoto S, Ochiai H, Shida D, Kanemitsu Y. Improving selection for resection of synchronous para-aortic lymph node metastases in colorectal cancer. Dig Surg 2019;36(05):369-375

13 Selman TJ, Mann C, Zamora J, Appleyard TL, Khan K. Diagnostic accuracy of tests for lymph node status in primary cervical cancer: a systematic review and meta-analysis. CMAJ 2008;178(07):855-862

14 Bipat S, Glas AS, Slors FJ, Zwinderman AH, Bossuyt PM, Stoker J. Rectal cancer: local staging and assessment of lymph node involvement with endoluminal US, CT, and MR imaging-a meta-analysis. Radiology 2004;232(03):773-783

15 Kennedy ED, Milot L, Fruitman M, et al. Development and implementation of a synoptic MRI report for preoperative staging of rectal cancer on a population-based level. Dis Colon Rectum 2014; 57(06):700-708

16 Sasaki K, Nozawa H, Kawai K, et al. Management of isolated paraaortic lymph node recurrence of colorectal cancer. Surg Today 2019 